\title{
O destronamento da aura e a mutação da percepção na era da arte pós-aurática em Walter Benjamin
}

\author{
Rogério Silva de Magalhães ${ }^{1^{*}}$
}

Resumo: Este artigo visa analisar duas questões conhecidas nos estudos benjaminianos: o declínio da aura na era da arte reprodutível e as mudanças na percepção dos indivíduos em relação à arte pós-aurática. Para dar conta dessas questões, faremos uma incursão na segunda versão do ensaio "A obra de arte na era de sua reprodutibilidade técnica" em busca das considerações de Benjamin sobre o cinema, forma de arte desauratizada por excelência, e, ao mesmo tempo, com o propósito de enriquecer a discussão, pretendemos refletir acerca das concepções de Eisenstein sobre o cinema, o qual considera que a função do filme é causar impacto na percepção do espectador. Tanto Eisenstein quanto Benjamin compartilham a mesma ideia sobre o potencial revolucionário do cinema.

Palavras-chave: aura - técnica - cinema - percepção - Benjamin.

\begin{abstract}
This article aims to analyze two well-known issues in the Benjaminian studies: the decline of the aura in the age of art reproduction and the changes in the individuals perception with regard to the post-auratic works of art. In order to address these issues, we will make inroads into the second version of the essay "The work of art in the age of its technological reproducibility" in search for Benjamin's considerations about cinema, the non-auratic form of art par excellence, and at the same time, with the purpose of enhancing the debate over the subject, we intend to ponder upon Eisenstein's Russian film, which considers that the function of the film is to impact the spectator's perception. Both Eisenstein and Benjamin share the same idea of the revolutionary potential of film.
\end{abstract}

Keywords: aura - technique - film - perception - Benjamin.

$1^{*}$ Mestre e doutorando em filosofia pela UNIFESP. 
O ensaio "A obra de arte na era de sua reprodutibilidade técnica", de Walter Benjamin, comporta duas questões que, apesar do tempo transcorrido desde a sua redação na metade da década de 1930, continuam extremamente atuais e ainda merecem, portanto, a nossa reflexão: o declínio da aura na arte reprodutível e a transformação da nossa percepção na era da arte pós-aurática. Ora, saber como ocorre o processo de desauratização da obra de arte no início do século XX não implica uma total desvinculação da segunda questão. Pelo contrário, há o entrelaçamento entre uma e outra. De fato, detectar na história, como faz Benjamin, o momento do declínio da "aura" na obra de arte na era de sua reprodução técnica parece ser uma questão inseparável da transição de uma forma de percepção essencialmente ótica da obra de arte aurática para uma de ordem ótica e tátil na desauratizada.

A questão do declínio da aura na obra de arte produzida no século $\mathrm{XX}$, principalmente naquela com forte influência do aparato mecânico, é, com efeito, colocada no centro de um debate não só sobre o seu desaparecimento devido ao surgimento de novas formas de manifestação artística, notadamente a fotografia e o cinema, com forte influência, portanto, do suporte técnico, mas também sobre a relação do espectador com o objeto de arte pós-aurático. Não é, portanto, somente a reprodução em si de uma obra de arte que está em jogo no ensaio, mas um processo muito mais específico que deflagra a destruição da aura: a reprodução técnica em massa.

Pretendemos aqui discutir não só os efeitos positivos desse processo para Benjamin, mas também o significado social do cinema para a massa de trabalhadores. Tomaremos como base para as reflexões contidas neste artigo a segunda versão do ensaio de Benjamin, publicada em 1936. Também configura nosso objetivo trazer à tona as concepções cinematográficas do 
cineasta russo Einsenstein e compará-las com as de Benjamin, pois este último manifesta grande respeito pelo cinema russo no ensaio. Almejamos não só compreender melhor o poder que o cinema possui de desviar o olhar para longe do cotidiano e, portanto, seu efeito na percepção dos indivíduos, como percebe Benjamin, mas, ao mesmo tempo, seu potencial emancipatório do sufocante regime capitalista de produção. O nosso trajeto não poderia desembocar em outra linha de chegada que não o cinema, pois este último é o tema central do ensaio.

\section{Crise da aura na obra de arte tradicional}

Nesse ensaio, Benjamin inicia sua investigação admitindo que a reprodução sempre existiu no mundo da arte. Antes do surgimento de tecnologias que possibilitassem a reprodução em massa de uma obra de arte como aquelas que se tornaram tão populares no século passado, $\mathrm{o}$ ato de imitar o original já era feito manualmente em outros períodos da história da humanidade. "A obra de arte sempre foi, por princípio, reprodutível. O que os homens fizeram sempre pôde ser imitado por homens. Tal imitação foi praticada igualmente por discípulos, para exercício da arte; por mestres, para difusão das obras; e, finalmente, por terceiros, ávidos de lucros". ${ }^{2}$ Portanto, não se trata de um processo essencialmente novo, isto é, ocorrido pela primeira vez no século XX. Contudo, no século passado, a reprodução técnica ganha novos contornos. Em termos de reprodução, a novidade reside no desenvolvimento de técnicas que permitem a reprodução em massa da obra de

2 BENJAMIN, W. A obra de arte na era de sua reprodutibilidade técnica. Trad. Francisco De Ambrosis Pinheiro Machado. Porto Alegre, RS: Zouk, 2012, p. 13. 
arte. A reprodução torna-se a forma de produção. A inovação do cinema reside justamente na proposta de modificação na própria forma de reprodução. Esse processo era inimaginável na arte tradicional. $\mathrm{O}$ que antes era limitado pela capacidade manual do pintor ou do escultor, agora, graças aos avanços da técnica, pode ser reproduzido sem qualquer tipo de restrição temporal ou quantitativa. Mas não é só isso. A reprodução técnica conferiu à cópia uma semelhança extraordinária em relação ao original. No entanto, por mais perfeita que seja essa cópia, segundo Benjamin, há algo que está ausente na obra de arte reproduzida: "Mesmo à mais perfeita reprodução falta um elemento: o aqui e agora da obra de arte - sua existência única no local onde se encontra. Nessa existência única, porém, e em nada mais, realiza-se a história à qual foi submetida no decorrer de seu existir". ${ }^{3}$

Vemos assim que a tradição que jaz no interior do original não pode ser transmitida para a reprodução. Milhares de camisetas com a imagem da Monalisa de Da Vinci, também conhecida como La Gioconda, podem ser confeccionadas todos os anos no mundo inteiro. Todavia, há apenas um quadro da Monalisa, o qual foi pintado entre 1503 e 1506 e se encontra atualmente no museu do Louvre em Paris. Essa presença única de uma obra em um determinado lugar dá alma ao objeto artístico. A autenticidade $(\text { Echtheit })^{4}$ da obra está, portanto, vinculada à tradição que esse

3 BENJAMIN, op. cit., 17.

4 Benjamin define autenticidade (Echtheit) como um conjunto de elementos intrínsecos à obra e que são transmitidos pela tradição. Essa composição constitui a identidade do objeto artístico. "A autenticidade de uma coisa é a quintessência de tudo aquilo que nela é transmissível desde a origem, de sua duração material até seu testemunho histórico. Na medida em que este se funda naquela, então, na reprodução, quando a duração material se subtrai aos homens, também o 
objeto carrega ao longo do tempo e que fornece o caráter de unicidade a ele. Ou seja, a unicidade é o sentido da obra no espaço e no tempo. Citando Benjamin: "O aqui e agora do original constitui o conceito de sua autenticidade e sobre o fundamento desta encontra-se a representação de uma tradição que conduziu esse objeto até os dias de hoje como sendo o mesmo e idêntico objeto". ${ }^{5}$ Pode-se constatar assim que a tradição de uma obra de arte repousa em sua continuidade ao longo do tempo. Essa presença contínua garante a autenticidade da obra de arte.

Por esse motivo, o quadro da Monalisa, embora tenha sido objeto de reprodução para fins artísticos como a Monalisa com bigodes de Marcel Duchamp ou comerciais como no verso de pequenos espelhos portáteis ou em camisetas, como observado anteriormente, mantém seu caráter de unicidade. Isso não representa pouca coisa se considerarmos que quando a obra é mencionada, a referência que vem à mente de imediato é o quadro de Da Vinci, tal qual como produzido pelo pintor no século XVI.

$\mathrm{Na}$ era da arte reprodutível, segundo Benjamin, essa existência única, esse "aqui e agora" (das Hier und Jetzt) da arte tradicional se encontra, contudo, ausente. A tradição que era responsável pela ressonância do objeto artístico do passado no tempo presente, isto é, pelo distanciamento temporal que garantia a reverência ao objeto no presente é destruída pela tecnologia de reprodução em massa. "A tradição atuava distanciando seus objetos como passado a fim de presentificá-los no presente; a

testemunho histórico da coisa é abalado. De certo, somente isso, mas o que desse modo é abalado é a autoridade da coisa, seu peso tradicional". Cf. op. cit., p. 21-23. 5 BENJAMIN, op. cit., p. 19. 
tecnologia, no entanto, destrói essa distância". ${ }^{6}$ Mas esse é apenas um dos efeitos da reprodução em massa da fotografia e do cinema. Mesmo que não haja nenhuma modificação no conteúdo da obra reproduzida como na era da técnica de reprodução em massa, ou seja, mesmo que as reproduções carreguem traços pictóricos idênticos ao original, a autenticidade do original não é transferida para a obra reproduzida. Por outro lado, a não modificação do conteúdo não é garantia de que o "aqui e agora" se manterá intacto. "Essas circunstâncias modificadas podem deixar, no mais, a constituição da obra intocada - desvalorizam, em todo o caso, seu aqui e agora". ${ }^{7} \mathrm{Na}$ verdade, o que Benjamin percebe com perspicácia é que, na era da arte tecnicamente reprodutível, devido ao alto grau de exposição, a autenticidade, a unicidade, enquanto elementos característicos da obra de arte tradicional, entram em declínio. Parece difícil negar que o surgimento do museu tenha fortalecido a condição de exposição de uma arte tradicional como a escultura e a pintura se fizermos uma comparação com a exposição de uma imagem em um ritual religioso. Nesse sentido, por sua originalidade, aliada a um grande valor de exposição, pode-se dizer que a escultura ainda nos remeteria a uma tradição de culto. Entretanto, no caso do cinema, o valor de exposição conduz à eliminação de qualquer vestígio de aura e, portanto, de culto da obra.

Consequentemente, isso tudo leva Benjamin a afirmar que a "aura" (Aura) da obra de arte tradicional está em franco declínio

6 CAYGILL, Howard. "Benjamin, Heidegger e a destruição da tradição". In: BENJAMIN, Andrew e OSBORNE, Peter (Orgs.). A filosofia de Walter Benjamin: destruição e experiência. Trad. Maria Luiza X. de A. Borges. Rio de Janeiro: Jorge Zahar, 1997, p. 40.

7 BENJAMIN, op. cit., p. 21. 
no mundo contemporâneo. Mas o que seria essa "aura" em fase de vaporização? "Um estranho tecido fino de espaço e tempo: aparição única de uma distância, por mais próxima que esteja". ${ }^{8}$ A experiência desse fenômeno é o que Benjamin descreve como "aura". Tudo aquilo que singulariza a obra de arte tradicional e que permite que ela seja fruída in loco por um indivíduo em sua singularidade cai em desuso na era da arte pós-aurática porque esta última se encontra exposta a todos. A aura era uma espécie de brisa que continha algo de sagrado nela. A aura era algo que vinha da tradição e que, por conseguinte, podia ser transmitida. Entendase por tradição a possibilidade de transmitir as experiências do passado para o presente. Segundo Benjamin, o desaparecimento da aura tem um significado que transborda o campo da arte:

o que desaparece na época da reprodutibilidade técnica da obra de arte é sua aura. Esse processo é sintomático; seu significado vai muito além da esfera da arte. A técnica de reprodução, assim se pode formular de modo geral, destaca o reproduzido da esfera da tradição. Na medida em que multiplica a reprodução, coloca no lugar de sua ocorrência única sua ocorrência em massa. ${ }^{9}$

A técnica não só diminui a "aura" na reprodução em massa, mas esta última se encontra praticamente ausente nas novas formas de expressão artística, tais como, a fotografia e inexistente no cinema. No caso da fotografia, ainda dizemos praticamente porque, para Benjamin, o último reduto da "aura" na arte tecnicamente reprodutível é a imagem do rosto de pessoas falecidas ou de

8 BENJAMIN, op. cit., p. 27.

9 BENJAMIN, op. cit., p. 23. 
amantes ausentes. Desse modo, o rosto seria o último bastião da "aura". Diante dessas fotos, o espectador realiza um ritual de contemplação do rosto humano similar ao que ocorria diante de uma pintura. ${ }^{10} \mathrm{O}$ aurático na fotografia de pessoas provoca a sensação de algo inabarcável. As fotos de pessoas falecidas ou de amantes ausentes retratam um momento que ficou congelado no tempo e espaço. Por conta das características do suporte em que se encontra a imagem revelada e, por consequência, diante das múltiplas possibilidades de exposição da imagem fotográfica, a fotografia promove, antes do cinema, o primeiro grande desgaste do valor de culto (Kultwert).

Com a fotografia, o valor de exposição começa a premir para trás o valor de culto em todas as frentes. Este, porém, não recua sem resistência. Ocupa uma última trincheira que é a face humana. Não é nada casual que o retrato era central nos primórdios da fotografia. No culto da recordação dos entes amados, distantes ou falecidos, o valor de culto da imagem encontrou seu último refúgio. $\mathrm{Na}$ expressão fugaz de um rosto humano, a aura acena

$10 \mathrm{Na}$ primeira fase do desenvolvimento da fotografia, a alta burguesia almejava ter seus rostos retratados. Durante o processo mecânico de produção da fotografia, uma aura era produzida em torno do rosto. Quando Benjamin faz referência às primeiras fotografias, ele tem em mente o primeiro estágio técnico de desenvolvimento destas. Desse modo, a aura desses retratos estaria intimamente associada ao nível de desenvolvimento técnico dos aparelhos. Em "Pequena história da fotografia", Benjamin argumenta que a aura nos retratos antigos está associada ao fenômeno do contraste da luz com a sombra. $\mathrm{O}$ rosto humano aparece na chapa como se tivesse um vapor ao seu redor. Após 1880, com os avanços no setor óptico, as objetivas captam uma quantidade maior de luz e a sombra é eliminada do processo. Nesse caso, a aura só pode ser criada artificialmente em uma foto por intermédio de um artifício chamado "off-set". Cf. BENJAMIN, W. "Pequena história da fotografia". In: Idem. Magia e técnica, arte e política: ensaios sobre literatura e história da cultura. São Paulo: Brasiliense, 1996, p. 98-99. 
das primeiras fotografias pela última vez. E é isso que perfaz sua beleza melancólica e incomparável. Onde, porém, o homem se retira da fotografia, ali, pela primeira vez, o valor de exposição se sobrepõe ao valor de culto. ${ }^{11}$

$\mathrm{Na}$ medida em que o valor de culto das imagens fotográficas nesses dois tipos específicos assinalados por Benjamin recrudesce, isto é, nas fotos da pessoa amada e nas dos entes falecidos, a qualidade da nossa experiência estética dos objetos de arte sofre uma metamorfose. $\mathrm{O}$ culto - aquele elemento quase religioso da obra de arte - cede lugar ao que Benjamin denomina "valor de exposição" (Ausstellungswert). Essa mudança radical de paradigma é desencadeada, basicamente, por dois fatores, ambos interligados: o primeiro está vinculado ao desenvolvimento acelerado da técnica e o segundo ao aumento da reprodução em massa da obra de arte. $\mathrm{O}$ resultado desse processo é um desinteresse por parte do público por esse "valor de culto" que ainda se faria presente na arte tradicional. Em seu Benjamin, Adorno, e o ocaso da aura, Rosen apresenta o seguinte comentário sobre esse processo:

[...] os processos 'dessacralizantes' da civilização moderna - o desenvolvimento do capitalismo industrial e o concomitante crescimento das massas - diminuíram, de mãos dadas com o fato puramente técnico do aumento da reprodutibilidade mecânica da obra de arte, o poder dos seres humanos de ver e reagir a essa qualidade. Assim, a singularidade da obra de arte torna-se cada vez mais questionável e conduz ao declínio de sua função de culto. ${ }^{12}$

11 BENJAMIN, W. A obra de arte na era de sua reprodutibilidade técnica, p. 45-47. 12 ROSEN, Michael. "Benjamin, Adorno, e o ocaso da aura". In: RUSH, Fred. 
Para Benjamin, o fotógrafo francês Eugène Atget (18571927) pode ser considerado um dos precursores dessa transição de uma arte auratizada para uma desauratizada ao captar com suas lentes os espaços urbanos vazios de Paris na primeira década do século XX. E, nesse processo de transição, surge uma mudança no modo de recepção.

Dar a esse processo o seu lugar próprio constitui o significado inigualável de Atget, que fixou as ruas de Paris, por volta de 1900, vazias de homens. Com muita justiça, dizia-se dele que as fotografou como um local de crime. Também esse é vazio de homens. [...]. Inquietam o observador; ele sente que para chegar até elas precisa procurar um caminho determinado. ${ }^{13}$

As fotos de Atget acenam, portanto, para uma mudança de postura por parte do observador que não é mais hipnotizado pela obra de arte aurática. Para Benjamin, ele não quer embelezar as suas imagens e nem eternizar imagens de entes falecidos com o intuito de enfeitiçar o espectador. Atget teria sido o primeiro a rejeitar o mundo da fotografia de retratos, fortemente vinculada à aura. Em "Pequena história da fotografia", de 1931, Benjamin já havia reconhecido que Atget purifica a atmosfera auratizante do retrato. O criticado por Benjamin aqui é o retrato retocado em "off-set" no fim do século XIX, cujo fim seria o de forjar uma pseudo-aura retrógada. "Ele saneia essa atmosfera, purifica-a: começa a libertar o objeto da sua aura, nisso consistindo o mérito mais incontestável da moderna escola fotográfica". ${ }^{14}$ Parece correto, então, afirmar que as fotos de Atget pendem assim mais

(Org.). Teoria crítica. São Paulo: Ideias \& Letras, 2008, p. 76.

13 BENJAMIN, op. cit., p. 47.

14 BENJAMIN, "Pequena história da fotografia". In op. cit., p. 98-99. 
para a contestação da realidade concreta do que para o culto. $\mathrm{Na}$ interpretação de Gagnebin:

Atget não fotografa 'vistas célebres' ou 'símbolos de uma cidade' como o fazem os turistas e os vendedores de cartões postais, mas registra imagens das filas de desempregados na busca de um trabalho, das carretas nos pátios internos de edifícios miseráveis, de mesas ainda sujas com garrafas de vinho barato. A maior parte dessas fotografias, ressalta Benjamin, mostra paisagens urbanas vazias, sem instantâneo anedótico que possa agradar, sem Stimmung, sem ambiente típico; esse vazio, essa pobreza dirá Benjamin em 'Experiência e pobreza', não significa somente a recusa de tornar mais bonita a realidade, mas permite também abrir um espaço de experimentação possível, [...]. ${ }^{15}$

O percurso realizado até o momento permite-nos dizer que, para Benjamin, a destruição da aura na arte reprodutível é um processo tão radical que altera a nossa experiência em relação aos objetos artísticos reproduzidos. Com a queda da aura, a possibilidade de experiência profunda em relação ao objeto se esvaece. Isso não significa necessariamente que a fotografia, por exemplo, não possa ser considerada como arte. Não ter "aura" não implica a revogação do status de arte da obra. Porém, ela certamente perde seu valor de culto. Diante da reprodutibilidade, não há, portanto, como manter o

15 GAGNEBIN, Jeanne Marie. "De uma estética da visibilidade a uma estética da tatibilidade em W. Benjamin". In: COLÓQUIO INTERNACIONAL ESTÉTICAS DO DESLOCAMENTO: DISCURSO FILOSÓFICO, TEORIA CRÍTICA E LINGUAGENS ARTÍSTICAS. Belo Horizonte. 2007. Anais. Organização do CD-ROM: Rodrigo Duarte e Imaculada Kangussu. Belo Horizonte: Associação Brasileira de Estética (ABRE), 2008, p. 4. 
mesmo olhar contemplativo da arte tradicional. O declínio da aura e, por conseguinte, do valor de culto da arte revela que o homem da contemporaneidade almeja estabelecer uma nova relação não só com os objetos artísticos, mas com as coisas do mundo.

Mas é o cinema o alvo central da reflexão benjaminiana porque a reprodução faz parte da constituição desta mídia. $\mathrm{O}$ cinema está no âmago da ruptura entre uma arte aurática e uma sem esse elemento.

Assim como no tempo primevo, a obra de arte, por meio do peso absoluto depositado sobre seu valor de culto, tornouse, em primeira linha, um instrumento da magia, que, de certa forma, somente mais tarde foi reconhecido como obra de arte. Do mesmo modo, hoje, por meio do peso absoluto depositado sobre o seu valor de exposição, a obra de arte torna-se uma figuração com funções totalmente novas, entre as quais se destaca aquela de que temos consciência, a função artística, que no futuro possivelmente será reconhecida como secundária. Certo é que atualmente o cinema oferece os elementos mais úteis para esse conhecimento. ${ }^{16}$

Permanecemos assim no campo das imagens, mas agora em movimento. No cinema (Film), por sua vez, a película não guarda nenhum resquício de aura, pois, conforme vimos nos parágrafos anteriores, não se trata de arte tradicional. A despeito de não mais possuir uma "aura", mesmo assim, como sabemos, Benjamin não deixa de considerá-la como arte. "Nunca antes as obras de arte foram tecnicamente reprodutíveis em escala tão elevada e em extensão tão ampla como hoje. No cinema temos uma forma, cujo caráter de arte, pela primeira vez, é determinado de parte a parte

16 BENJAMIN, A obra de arte na era de sua reprodutibilidade técnica. p. 39. 
por sua reprodutibilidade". ${ }^{17}$ Gasché entende esse movimento da seguinte forma:

$\mathrm{Na}$ arte mecanicamente reprodutível, esse vínculo essencial entre arte e culto é completamente rompido. A arte na era da reprodutibilidade mecânica é uma arte que não tem mais sequer uma função ritualística secular. A crise é radical: despojada de seu valor de culto num sentido mágico, religioso e secularizado, a arte tornou-se inteiramente profana, livre de todas essas dependências. ${ }^{18}$

Os valores anteriormente considerados vitais para manter viva a tradição da obra de arte tradicional, tais como a unicidade, a autenticidade e a aura, se tornam desnecessários para essa nova técnica chamada cinema.

\section{O cinema como desalienação do homem}

Segundo Benjamin, o que há de mais artístico no cinema não é o fato das imagens estarem em movimento e existir um enredo que compõe uma história para essas imagens desauratizadas. Nem tão pouco o fato do cinema permitir a transposição de gêneros textuais com alta dose de fantasia como o terror e a ficção-científica para a grande tela. ${ }^{19}$ Mas sim a arte

17 BENJAMIN, op. cit., p. 49-51.

18 GASCHÉ, Rodolphe. "Digressões objetivas: sobre alguns temas kantianos em 'A obra de arte na era de sua reprodutibilidade técnica' de Benjamin". In: OSBORNE, P. e BENJAMIN, Andrew (Orgs.). A filosofia de Walter Benjamin: destruição e experiência, p. 195.

19 De fato, o surgimento do cinema abriu portas quase infinitas para a materialização 
no processo de montagem (Montage) do filme. "A obra de arte surge aqui somente em razão da montagem. De uma montagem, na qual cada componente individual é a reprodução de um acontecimento, que não é em si mesmo uma obra de arte, nem resulta em uma obra de arte pela fotografia" ${ }^{20}$ Essa questão da montagem cinematográfica não é gratuita no ensaio de Benjamin. Não se presta somente a estabelecer uma diferenciação radical em relação à arte tradicional, isto é, enfatizar a inexistência da aura no cinema. Essa questão e, por consequência, a da abordagem do cinema em Benjamin, é de suma relevância para compreender a mudança drástica que ocorre em nossa percepção na era da arte pós-aurática. "Mas, diferentemente dos conterrâneos, seu interesse não era primordialmente a influência do cinema na arte e na cultura, ou suas características estéticas, mas a mudança que as imagens fabricadas tecnicamente provocavam na percepção e na arte". ${ }^{21}$ Veremos, a seguir, como se realiza essa mudança.

em fotograma do que só podia ser apreendido antes pela linguagem literária. O primeiro filme de ficção-científica de que se tem história foi o Le Voyage dans la Lune (1902) de Georges Méliès (1861-1938). Contudo, um dos mais famosos do gênero até o fim da década de 30 foi o filme Metrópolis (1926) de Fritz Lang (1890-1976). No caso do gênero de terror, o primeiro filme teria sido Le Manoir du Diable (1896), também de Georges Méliès. O segundo seria Frankenstein de Thomas Edison (1847-1931) produzido em 1910. No entanto, o primeiro grande sucesso do gênero teria sido $O$ Gabinete do Dr. Caligari de 1919. O primeiro filme sobre vampiros só surgiria três anos mais tarde, isto é, em 1922, na Alemanha: Nosferatu de Murnau (1888-1931). Em todos esses filmes, já se nota a presença de algo que se tornará a marca registrada do cinema: os efeitos de luz. Mas esses exemplos também nos revelam algo mais e de grande interesse para Benjamin: o enorme potencial da técnica no cinema e o impacto desta em nossa percepção ao sermos defrontados com todas as imagens em movimento.

20 BENJAMIN, op. cit., p. 59.

21 SCHÖTTKER, Detlev. "Comentários sobre Benjamin e 'A obra de arte"”. In: 
Não é só o fenômeno do declínio da aura que se efetua na era da reprodutibilidade técnica. Outro efeito visível é a relação entre o espectador e a obra de arte que se modifica drasticamente com o surgimento do cinema. "A reprodutibilidade técnica da obra de arte altera a relação da massa com a arte. De uma atitude extremamente retrógada diante, por exemplo, de um Picasso, passa a uma relação extremamente progressista em face, por exemplo, de um Chaplin". ${ }^{22}$ Essa mudança se desenvolve em dois níveis: o primeiro é o da produção em série que vem a atender uma exigência da massa. $\mathrm{O}$ objetivo é trazer a arte para perto do grande público. $\mathrm{O}$ segundo ocorre no nível da recepção. $\mathrm{Na}$ arte aurática, lembremos que a percepção do espectador é permeada pelo "valor de culto" da obra. O ritual de contemplação exige um contato intimista com o objeto. Em outras palavras, exige-se um recolhimento do indivíduo diante da obra. Não se vislumbra assim a possibilidade de apreciação de um quadro por um grande número de pessoas em um mesmo espaço e ao mesmo tempo. Aliás, esse nunca foi o objetivo original dos pintores ao retratarem suas impressões da realidade em seus quadros.

Um quadro sempre teve a peculiar pretensão de ser contemplado por um ou por poucos. A contemplação simultânea de quadros por um grande público, o que passou a ocorrer no século XIX, é um primeiro sintoma da crise da pintura. Crise que, de modo algum, foi desencadeada somente pela fotografia, mas, de modo relativamente independente dela, também por meio da

BENJAMIN, Walter et al. Benjamin e a obra de arte: técnica, imagem, percepção. Trad. Marijane Lisboa e Vera Ribeiro. Rio de Janeiro: Contraponto, 2012, p. 43. 22 BENJAMIN, op. cit., p. 91. 
pretensão da obra de arte dirigida à massa. ${ }^{23}$

Para Benjamin, a própria crise aurática da pintura se deve, então, a um fato histórico deflagrado ainda no século XIX e parece ser possível pensarmos retroativamente ao século XVIII em que o notável interesse da alta burguesia pela arte provoca o fenômeno de sobreposição do valor de exposição em detrimento do culto e, portanto, uma laicização da arte. A crise da pintura não é assim só simples obra do surgimento da fotografia, mas está associada a um aumento de público interessado nessa forma de arte. Benjamin argumenta que a pintura - podemos conjeturar que isso se deva, provavelmente, por conta de seu formato estritamente pictórico encerrado na estrutura física da tela - não pode ser objeto de apreciação coletiva (Kollektivrezeption). "A pintura, de fato, não está em condições de oferecer o objeto de uma recepção coletiva simultânea, tal como sempre foi o caso da arquitetura, como antes foi o caso do poema épico e como hoje é o caso do cinema". ${ }^{24}$ Para uma recepção coletiva, conforme exemplos fornecidos pelo próprio Benjamin, se faz necessário outro tipo de experiência, além da ocular. Ao comentar a evaporação do valor de culto na arte desauratizada e sobre a experiência singular e coletiva da obra de arte, escreve Gasché:

Concentração, contemplação, absorção pressupõem um único espectador, ou muito poucos que, diante da obra de arte autêntica, dotada de autoridade, perdem o poder de controlar a si mesmos, ou aos outros. $\mathrm{O}$ espectador de um filme, em contrapartida, não é mais um só espectador singular. É desde o início um público

23 BENJAMIN, op. cit., p. 93.

24 BENJAMIN, op. cit., p. 93. 
numeroso, um sujeito coletivo. Para a massa de indivíduos reunida no cinema, concentração ou contemplação da obra de arte estão fora de questão. ${ }^{25}$

O fato do cinema ser visto por um grande número de pessoas constitui, portanto, por si só uma mudança na perspectiva de percepção do observador. A estrutura espacial-temporal se modifica na arte reprodutível. A relação do homem com a tradição, que jazia por detrás da arte aurática, se faz desnecessária para compreender o filme. Na obra de arte aurática, há a exigência de um distanciamento do observador em relação ao objeto. Isso constitui, na verdade, uma das características da arte aurática. "A característica temporal da aura é sua unicidade (Einmaligkeit) e sua característica espacial é a distância". ${ }^{26}$ Mas é importante atentarmos para o fato de que esse distanciamento não é, obviamente, um ato físico. $\mathrm{O}$ distanciamento é ato que permite ao receptor mergulhar na obra de arte com aura. $\mathrm{O}$ cinema implode com a necessidade da submersão no objeto para que o indivíduo possa ficar o mais próximo da aura. Na obra de arte pós-aurática, aquela sob a égide da técnica, esse elemento se atrofia, bem como todos os outros vinculados a ela. Em Édipo e o anjo: itinerários freudianos em Walter Benjamin, Rouanet diz:

Com a multiplicação dos meios de reprodução técnica, principalmente a fotografia, essa estrutura espaço-temporal

25 GASCHÉ, Rodolphe. op. cit., p. 206.

26 ROUANET, Sérgio P. Édipo e o anjo: itinerários freudianos em Walter Benjamin. $2^{\mathrm{a}}$ ed. Rio de Janeio: Tempo Brasileiro, 1990, p. 55. 
da obra de arte se modifica. Reprodutível ao infinito, ela deixa de ser única, e pode, ao mesmo tempo, ser tocada pelo observador, deixando de ser longínqua. A arte perde sua aura. Aos poucos, essa reprodutibilidade deixa de ser externa à obra, e passa a determiná-la em sua estrutura. Ela é produzida para ser reproduzida. Com o advento do cinema, essa tendência atinge seu clímax: a reprodutibilidade técnica da obra cinematográfica se funda imediatamente na técnica de sua produção. ${ }^{27}$

Porém, a transformação não é só de cunho espacial, mas também sensorial. Essa afirmação possui dois alvos: em primeiro lugar, denunciar que a contemplação (Kontemplation) já não se faz possível na linguagem cinematográfica. Ou seja, a necessidade de relação única com a obra desaparece em definitivo. Em segundo lugar, a percepção sensorial do indivíduo é golpeada por sucessivas ondas de imagens e, na era do filme sonoro, por sons, sejam eles verbais ou musicais. Isso ajuda a explicar por que não há tempo viável para a contemplação singularizada como na pintura.

Compare-se a tela sobre a qual o filme se desenrola com a tela sobre a qual se encontra uma pintura. A imagem de uma altera-se, a da outra não. A última convida o espectador à contemplação; diante dela, ele pode se entregar ao desenrolar de suas próprias associações. Diante do registro cinematográfico, isso não é possível. ${ }^{28}$

27 BENJAMIN, op. cit., p. 55.

28 BENJAMIN, op. cit., p. 108. 
Nota-se que enquanto na pintura há uma predominância do aparelho ótico na apreciação da obra de arte, no cinema, conforme dito anteriormente, a relação do indivíduo com a tela grande exige outro tipo de aproximação. De acordo com Benjamin, essa transformação histórica da percepção dá seus primeiros passos com o surgimento do dadaísmo 29 . "De fato, as manifestações dadaístas garantiram uma distração muito veemente, ao transformarem a obra de arte no centro de escândalo. Tinha, sobretudo, uma exigência a satisfazer: provocar a indignação pública" ${ }^{30} \mathrm{E}$, no parágrafo seguinte do ensaio sobre a obra de arte, Benjamin acrescenta: "De uma aparência sedutora aos olhos

29 A palavra "dada" faz parte da linguagem infantil e não possui significado específico. O dadaísmo foi um movimento artístico crítico que produziu uma arte experimental de contestação nas duas primeiras décadas do século XX. A marca principal do movimento foi o forte experimentalismo disforme na montagem de suas obras. Os artistas relacionavam e combinavam elementos díspares em seus trabalhos de forma a causar um impacto no observador. "[...], Marcel Duchamp (1887-1968) prepara o dadaísmo, ao levar a arte ad absurdum, isolando completamente simples objetos de uso cotidiano [...], retirando-os da vida, privando-os de sentido e declarando-os obra de arte. Um prazer estético na forma especial do objeto não deveria fazer com que se levasse o quadro a "sério"". Cf. BAUMGART, Fritz. Breve história da arte. Trad. Marcos Holler. São Paulo: Martins Fontes, 2007, p. 348-349. O dadaísmo se firma como protesto contra uma civilização que não conseguiu evitar a eclosão da Primeira Guerra Mundial. "A vivência da guerra com suas vítimas e destruições insensatas causou uma rejeição a todos os 'valores' tradicionais, que se haviam mostrado completamente inúteis e incapazes para evitar tal catástrofe". Cf. BAUMGART, Fritz. op. cit., p. 349. Alguns dos expoentes principais desse movimento foram Tristan Tzara (18961963), Hugo Ball (1886-1927), Max Ernst (1891-1976), Marcel Duchamp (18871968) e Hans Arp (1886-1966). É bem provável que o que tenha atraído o olhar de Benjamin para as artes vanguardistas do início do século XX tenha sido o fato dessas artes valorizarem o procedimento, ou seja, uma comunicação que nasce de códigos articulados.

30 BENJAMIN, op. cit., p. 107. 
ou de uma convincente imagem sonora a obra de arte convertiase, com os dadaístas, em um projétil. Atingia com violência o espectador. Ganhava uma qualidade tátil". ${ }^{31}$

Mas é somente com o surgimento do cinema que uma alteração substancial na percepção se concretiza plenamente no ser humano. Como exposto antes, o distanciamento em relação ao objeto artístico, onde predominava o valor de culto, cede lugar a um vínculo mais próximo do indivíduo com o objeto, isto é, a relação espacial com o objeto artístico é alterada. A respeito da imagem no cinema e a experiência de Benjamin, Bolz comenta o seguinte:

O cinema produz uma imagem peculiar do mundo, uma imagem que é jeitosa e operacional, e não contemplativa e distanciada. É jeitosa porque dá para lidar com ela. É o resultado do fato técnico de que a câmara parte o todo do mundo das imagens em pedaços. [...]. Segundo a experiência de Benjamin, não é mais possível a gente submergir, se aprofundar nas imagens do cinema. Portanto, não é mais possível comportar-se contemplativamente diante delas. ${ }^{32}$

A percepção da obra cinematográfica passa a ser não somente de nível ótico para se tornar tátil (taktische) também. Embora o ótico não tenha perdido seu status na era da reprodução técnica da obra de arte, se faz necessário lembrar, mais uma vez, que a postura do sujeito diante da tela não é mais contemplativa como

31 Idem.

32 BOLZ, Norbert W. e FONTAINE, Michael de la. "Onde encontrar a diferença entre uma obra de arte e uma mercadoria?" Revista USP, São Paulo, n. 15, p. 96, set/out/nov. 1992. 
na arte tradicional. "Com isso, facilitou a demanda pelo cinema, cujo elemento de distração é também, em primeira linha, um elemento tátil, nomeadamente, baseado na mudança de cenas e de enquadramentos, que avançam em golpes sobre o espectador". ${ }^{33}$ Se, antes a pintura exigia o olhar atento do observador, isto é, atenção e recolhimento (Sammlung), no cinema, a percepção é distraída (zerstreute), pois o ritmo solicitado da percepção para acolher a linguagem cinematográfica é muito mais acelerado do que na pintura. Com o ritmo frenético da animação das imagens cinematográficas, a percepção precisa desenvolver estratégias diferenciadas de apreensão do que é exop. cit.o porque a mensagem do filme não está no enredo como comumente se pensa, mas na forma como as imagens são justapostas umas às outras e no choque que essa edição do filme provoca no espectador. "Benjamin considera que as possibilidades técnicas da fotografia e do cinema modificam não só o mundo das imagens, mas também o mundo perceptível, contribuindo para um aprofundamento da nossa apreensão". ${ }^{34}$

Por isso, o sistema perceptivo do espectador é transformado ao admitir a variante tátil. A percepção ocular é aquela que ocorre em nosso interior. Ela é o canal de conexão entre o nosso interior e a nossa experiência estética com o exterior. No cinema, além da tatibilidade que entra em ação, o próprio aparelho ótico sofre alterações porque exige-se muito mais do espectador. Nas palavras de Benjamin: "A recepção na distração, que se observa com intensidade cada vez maior em todos os domínios da arte e que é sintoma de uma profunda mudança da apercepção, tem no

33 BENJAMIN, op. cit.., p. 107-109.

34 SCHÖTTKER, Detlev. op. cit., p. 78. 
cinema seu instrumento de exercício próprio. Por seu efeito de choque, o cinema vem ao encontro dessa forma de recepção". ${ }^{35}$ Talvez tenha sido essa a grande descoberta de Benjamin, isto é, a do declínio completo da aura diante do surgimento de uma mídia como o cinema que altera a percepção do objeto e massifica a recepção. Se, por um lado, Benjamin não nega o pioneirismo dos artistas de movimentos como o dadaísmo - um movimento consciente e intencional por parte dos artistas -, por outro, só o cinema possui os instrumentos técnicos necessários para realizar as alterações operadas no modo de percepção do espectador.

A alma do cinema não está, de forma alguma, no enredo ou nos atores, mas na técnica de montagem. De fato, contrariamente ao senso comum, o enredo se constrói no processo de montagem do filme. É a montagem que permite a produção de sentido em uma obra cinematográfica. Embora esteja, em certa medida, interligada a toda essa reflexão benjaminiana sobre o declínio da "aura" na arte mecanicamente reprodutível e sobre as mudanças ocorridas na percepção do objeto de arte pós-aurático, o ponto central para Benjamin parece residir na forma como o cinema afeta a nossa recepção de uma obra. Nesse sentido, como atestado antes, a montagem exerce um papel fundamental para percebermos a guinada na percepção gerada pela criação do cinema. No artigo, "Onde encontrar a diferença entre uma obra de arte e uma mercadoria?", Bolz relata que o interesse de Benjamin pelo cinema reside na montagem porque esta dita o ritmo da sensação:

[...], o que interessa na teoria de Benjamin nada tem a ver com o conteúdo dos filmes, mas única e exclusivamente com a sua

35 BENJAMIN, op. cit., p. 115. 
forma. Esta constatação é importante, para que não haja malentendidos a respeito do que segue, porque a nova percepção do tempo, este novo ritmo irregular, feito de empurrões, com as suas superposições e montagens, corresponde a um fluxo de notícias, a um fluxo de dados que é afunilado pelo princípio seletivo da sensação. Portanto, a sensação é, por assim dizer, o critério, também o critério de seleção para este novo fluxo de dados e notícias. ${ }^{36}$

Por meio da lente da câmera, o choque de imagens da linguagem cinematográfica incita o alargamento da nossa limitada capacidade de percepção humana. "A câmara mergulha tão profundamente no objeto que percebe o que nele não é perceptível, e sem sair dele, capta dimensões que o transcendem". ${ }^{37}$ Desse modo, pode-se dizer que o dispositivo eletrônico da câmera permite ao homem um contato totalmente novo com a realidade, mas, ao mesmo tempo, exige uma reeducação do nosso aparelho perceptivo. Com ele, passamos a ter outra visão do mundo que nos rodeia. Nas palavras de Benjamin:

Dessa forma, a apresentação cinematográfica da realidade possui um significado incomparavelmente maior para o homem atual, pois fornece o aspecto livre de aparelho da realidade, que ele tem o direito de exigir da obra de arte, baseada justamente na penetração mais intensiva da realidade com o aparato. ${ }^{38}$

36 BOLZ; FONTAINE, op. cit., p. 95.

37 ROUANET, op. cit., p. 12.

38 BENJAMIN, op. cit., p. 89. 
No artigo "Onde encontrar a diferença entre uma obra de arte e uma mercadoria?", Bolz argumenta que a nossa capacidade de percepção é expandida graças aos instrumentos ópticos como a lente das câmeras cinematográficas. A natureza adquire outra dimensão para o sujeito ao ser mediada pela câmera. Ele escreve:

O olho natural somente nos oferece o mundo cotidiano que, para nós, não tem qualquer qualidade de conhecimento, de entendimento. $\mathrm{O}$ argumento de Benjamin consiste em dizer que a lente, as diversas possibilidades da lente da câmara, assim como a condução da câmara, nos libertam da ótica dos nossos olhos naturais e nos apresentam mundos, nos mostram recortes de uma espécie antifísica, contranatural, na qual se delineiam nitidamente formações estruturais às quais o nosso olho natural nunca teria acesso. Esta seria, pois, uma forma de conhecimento através de uma ótica antifísica. ${ }^{39}$

A montagem cinematográfica cobra do espectador uma reestruturação de seu sistema perceptivo culminando, inclusive, no resgate da dimensão tátil para a apreensão do objeto fílmico. Sob essas condições, a percepção é diametralmente afetada quando confrontada com um bombardeio daquilo que chamamos de imagens em movimento, isto é, imagens animadas. Resta ao espectador adotar um comportamento vigilante em relação à tela sob pena do indivíduo se perder nesse turbilhão de imagens animadas chamado cinema. "O desenrolar das associações daquele que o observa é imediatamente interrompido por meio de sua transformação. Nisso se baseia o efeito de choque do cinema, que, como todo efeito de

39 BOLZ; FONTAINE, op. cit., p. 95. 
choque, requer ser captado por meio de uma presença de espírito intensificada" ${ }^{40} \mathrm{E}$, em relação ao condicionamento imposto ao espectador pelo cinema, Rouanet escreve:

Enquanto na obra de arte clássica o observador podia divagar livremente, perdendo-se em suas fantasias, no cinema as imagens são imperiosas, impondo uma visibilidade autoritária, que proíbe ao espectador associações de ideias alheias ao que está sendo visto. Ele tem que estar totalmente presente, pois de outra forma os choques da imagem não poderiam ser absorvidos, [...]. ${ }^{41}$

Não é por acaso que Benjamin, em sua época, tinha uma admiração e interesse especial pelos filmes russos. Ele não nutria o sentimento de l'art pour l'art diante do cinema russo, mas via neste uma função prática. Bolz comenta: "É necessário lembrar o que já afirmei, que Benjamin vê a emancipação da nova mídia como sendo equivalente a uma emancipação do ser humano". ${ }^{42}$ Benjamin via também nesse tipo de cinema a expressão de um formato específico de montagem. De fato, os cineastas russos se preocupam imensamente com o processo de montagem de seus filmes, pois é por intermédio desse trabalho que se chegaria ao efeito desejado de uma experiência coletiva no público. Para os russos desse período histórico, o cinema constitui um sistema modelizante, isto é, um modelo de construção de um conhecimento de mundo compartilhado. O cinema de Eisenstein, sobretudo dos

40 BENJAMIN, op. cit., p. 108.

41 ROUANET, op. cit., p. 47.

42 BOLZ; FONTAINE, op. cit, p. 96. 
primeiros filmes, parece ilustrar bem o que fascinava Benjamin na montagem de um filme. "E no seu filme $O$ encouraçado Potemkin (1925), Sergei Eisenstein havia transformado o processo da montagem fílmica em uma forma artística própria, graças à qual ele será conhecido na Alemanha, como comenta Benjamin em artigo sobre o cinema russo". ${ }^{43}$ Por esse motivo, faremos, a partir deste momento, uma breve digressão sobre o pensamento cinematográfico de Eisenstein. Perceberemos fortes similitudes entre as concepções de Benjamin sobre o cinema e as de Eisenstein.

\section{3. $O$ cinema de Eisenstein}

O foco central da teoria eisensteiniana sobre o filme reside na ideia de que a montagem deve favorecer a produção de conhecimento no espectador. É função do cineasta reorganizar os elementos primários do plano como a luz e o movimento a fim de gerar conflito na mente do espectador.

Para Eisenstein (1898-1948), a preocupação e meticulosidade não se esgotam na justaposição de planos, mas se estende a uma busca por harmonia entre um trabalho interno nos planos isolados e a justaposição entre eles. De posse da ideia de que o plano é a unidade mínima do filme, Eisenstein maximiza o potencial do plano em duas frentes. Na primeira, ele pensa que cada plano em si causa um efeito psicológico no espectador e que esse plano individual pode ser combinado com outros para produzir um determinado efeito no filme como um todo. $\mathrm{Na}$ segunda, Eisenstein concebe que isoladamente cada plano carrega

43 SCHÖTTKER, op. cit., p. 48. 
em sua concepção uma série de elementos que podem gerar um turbilhão de choques. Isso significa que a relação do cineasta pode ser móvel com os planos, ou seja, é possível controlá-los para se obter um determinado efeito. $\mathrm{O}$ cineasta não deve, portanto, se submeter voluntariamente à matéria-prima do plano captada pela câmera, mas deve demonstrar uma atitude de irrequietude em relação à realidade existente do plano.

Eisenstein nunca poderia aceitar a noção do plano como um pedaço da realidade do qual o cineasta se apodera. Ele insistia de modo tão obstinado quanto lhe era possível em que o plano era o locus de elementos formais como iluminação, linha, movimento e volume. O sentido natural do plano não precisa, não deveria, dominar nossa experiência. ${ }^{44}$

$\mathrm{O}$ que Eisenstein busca não é exibir um tema para o espectador. Não se limita assim a unir os planos para que o espectador entenda o mote geral da história. Ele não quer uma simples associação de planos como técnica de produção de filmes em estúdio, mas, realizar uma colisão de planos para gerar choque no espectador.

Para a linguagem funcionar da melhor forma possível é preciso haver uma seleção correta de palavras, sons, imagens e a sua devida combinação na montagem para que se possa criar a sensação de choque. Para Eisenstein, o fragmento constitui o elemento da natureza com o mais alto grau de inclinação para a distorção. É esse fragmento que constitui o plano, isto é, o material básico para a estruturação da cena e a engenhosidade na combinação dos planos recebe o nome de montagem.

44 ANDREW, Dudley J. As principais teorias do cinema: uma introdução. Trad. Teresa Ottoni. Rio de Janeiro: Jorge Zahar, 2002, p. 52. 
A respeito da rejeição de Eisenstein à ideia de que um filme deve ser apenas uma colagem de planos, Leone e Mourão oferecem o seguinte comentário:

O correto, para Eisenstein, seria, então, passar a ocupar-se da natureza do princípio unificador, ou seja, que o conteúdo das imagens fosse conseguido não somente através de uma justaposição de plano, mas, também, através de um trabalho interno ao próprio plano [...]. Assim, os planos isolados e sua justaposição estarão em correta e mútua relação. ${ }^{45}$

Em última instância, para Eisenstein, todo esse trabalho com a montagem deve resultar em um desencadeamento de emoções.

Para Eisenstein, num primeiro momento, o plano era a menor unidade do filme. Ao ser combinado com outros planos, criava estímulos psicológicos e construía o todo. A montagem, através de corte, era deflagradora de emoções; a articulação dos planos ia-se desenvolvendo a partir de atritos, conflitos e choques que ia empurrando o filme para a frente. ${ }^{46}$

A combinação de todos esses elementos tem o papel de transcender o imediatismo da realidade cotidiana. Não são, desse modo, meros elementos de apoio para contar uma determinada história. O enredo do filme, ou seja, a história nua e crua extraída

45 LEONE, Eduardo e MOURÃO, Maria D. Cinema e montagem. $2^{\mathrm{a}}$ ed. São Paulo: Ática, 1993, p. 53.

46 LEONE; MOURÃO, op. cit., p. 60. 
do real cotidiano exposto diante de nossos olhos não pode exercer a função de protagonista sob pena de não provocar nenhum estímulo no espectador.

Logo após sua experiência com o teatro kabuqui, Eisenstein desejou criar para o cinema um sistema em que todos os elementos seriam iguais e comensuráveis: iluminação, composição, interpretação, história, mesmo legendadas devem ser interrelacionadas, a fim de que o filme possa escapar do realismo cru de apenas contar uma história acompanhada por elementos de apoio. Eisenstein afirmou que cada elemento funciona como uma atração circense, diferente das outras atrações do parque de diversões, mas em pé de igualdade e capaz de dar ao espectador uma impressão psicológica precisa. Isso é bem diferente da estética convencional que considera a iluminação, a perucaria, o trabalho de câmara e assim por diante como apoio da ação dominante, criando uma impressão ampla. Para Eisenstein, ver um filme é como ser sacudido por uma cadeia contínua de choques vindos de cada um dos vários elementos do espetáculo cinematográfico, não apenas do enredo. ${ }^{47}$

Até mesmo a legenda nos filmes de Eisenstein serve para atingir esse fim. Nenhum dos elementos constitutivos em cada plano de seus filmes está lá por acaso, isto é, para enfeitar ou dar charme à cena.

Eisenstein, [...], procurou experimentar as legendas com contraponto dramático: as diferentes tensões dramáticas eram,

47 ANDREW, op. cit., p. 50. 
nas legendas, compostas com letras de tamanhos diversos que, segundo esse cineasta, dariam a "sonoridade" necessária ao espectador, para que este experimentasse a ênfase dramática, como se fosse emitida pelo ator. ${ }^{48}$

Tudo o que acaba de ser dito aqui pode ser constatado em uma das obras-primas de Eisenstein: $O$ Encouraçado Potemkin de 1925. O filme é composto por cinco atos: 1) Homens e vermes; 2) Drama no tombadilho; 3) Apelo do morto; 4) A escadaria de Odessa; 5) Encontro com a esquadra. Essa divisão é apresentada pelo próprio Eisenstein em seu A forma do filme. Para atingir os nossos propósitos, tomaremos como objeto de uma curta análise o quarto ato. A ação começa com a população de Odessa saudando os revoltosos. ${ }^{49}$ Pelas vestimentas, nota-se que são pessoas de diversas classes sociais. São adultos de meia idade, jovens, crianças e idosos comemorando a insurgência dos marinheiros revoltosos do encouraçado. A ideia nessa cena parece ser a de que todos podem participar da revolução. O clima é de pura descontração. Naqueles poucos minutos de duração da comemoração, um ar de completa calmaria inunda o lugar. A música tocada durante o plano da comemoração oferece ao espectador uma sensação de júbilo. A partir daí, no entanto, Eisenstein monta, por intermédio da música, um espaço onde essas relações são entrecortadas por planos mais fechados e, ao mesmo tempo, abertos para construir

48 LEONE; MOURÃO, op. cit., p. 19.

49 Em relação à imagem das massas presente na obra cinematográfica, Benjamin compreende que elas não são espectadores passivos, mas são atores amadores ou, como ele mesmo afirma, "semi-especialistas". No caso do cinema russo, Benjamin afirma que os atores não são celebridades e nem intérpretes profissionais. Cf. BENJAMIN, op. cit., p. 77-83. 
o tempo da repressão dos revoltosos. De repente, os cossacos, representantes militares do poder czarista, descem a escada atirando contra a população local, a qual foge desesperadamente para salvar suas vidas. Nesse instante, a música passa a ser mais intensa, acelerada e sua utilização ajuda a definir toda a espacialidade e dramaticidade da cena. A música no Encouraçado Potemkin não é, portanto, um elemento decorativo, isto é, que serve para entreter a plateia. Composta por Edmund Meisel, a música deve incorporar a estrutura da obra. Incorporar significa conversão simbiótica entre imagem e som. Em A forma do filme, Eisenstein escreve:

Assim foi o Potemkin, naquele momento, que estilisticamente ultrapassou os limites do 'filme mudo com ilustrações musicais' em direção a uma nova esfera - o filme sonoro, onde verdadeiros modelos desta forma artística vivem numa unidade de imagens musicais e visuais fundidas, que compõem a obra através de uma imagem audiovisual unificada. Exatamente graças a estes elementos, que antecipam as potencialidades de uma substância interna da composição do filme sonoro, a sequência de 'Encontro com Esquadra' (que, com as 'escadarias de Odessa', teve um efeito tão ‘esmagador' no exterior) merece um lugar de destaque na antologia do cinema. ${ }^{50}$

$\mathrm{Na}$ época de Eisenstein, o desenvolvimento técnico do cinema levou à criação do filme falado. O cinema norteamericano fez uso extensivo desse recurso em suas produções

50 EISENSTEIN, Sergei. A forma do filme. Trad. Teresa Ottoni. Rio de Janeiro: Jorge Zahar, 2002, p. 161. 
com o intuito de aumentar, como vimos antes, além da captação literal da realidade do plano, a sensação de realismo do espectador. Eisenstein não se mostra nem um pouco interessado nesse tipo de método cinematográfico. O que ele faz não é aceitar passivamente o elemento bruto do plano, mas, subverte a sua natureza. Ele faz isso com os sons, "permitindo-lhes funcionar justapostos em contraponto com os outros elementos do filme. Eles proporcionavam, desse modo, uma nova variação de sons na escala que podia ser integrada à experiência artística pelo cinemacompositor através da energia da construção da montagem". ${ }^{51}$

Ainda em relação ao Encouraçado Potemkin, é preciso dizer que a imagem da marcha dos soldados contra a população local constrói essa dramaticidade na medida em que estão em descompasso com os cortes das cenas. Pode-se dizer que isso constitui parte do processo, pois o ápice da tensão reside mesmo no movimento de transição da marcha dos soldados contra os rebeldes em direção ao ritmo de descida do carinho de bebê na escadaria. A tensão da aceleração é obtida por intermédio da violação da ordem métrica do plano, isto é, do rompimento do comprimento dos passos dos cossacos e da velocidade do carrinho.

A sequência da 'escadaria de Odessa', em Potemkin, é um exemplo claro disto. Nela, a marcha rítmica dos pés dos soldados descendo as escadas viola todas as exigências métricas. Esta marcha, que não está sincronizada com o ritmo dos cortes, chega sempre fora de tempo, e esse mesmo plano se apresenta como uma solução completamente diferente em cada uma de suas novas aparições. O impulso final da tensão é proporcionado

51 ANDREW, Dudley J. op. cit., p. 55. 
pela transferência do ritmo dos pés descendo para outro ritmo - um novo tipo de movimento para baixo - o próximo nível de intensidade da mesma atividade - o carrinho de bebê rolando escada abaixo. O carrinho funciona como um acelerador, diretamente progressivo, dos pés que avançam. A descida degrau a degrau passa a descida de roldão. ${ }^{52}$

Antes de prosseguirmos, cabe fazermos um breve parêntese para explicar que a música é apenas um dos elementos constituintes da modelização do espaço da cena. Não é o único. É preciso ter isso em mente quando nos referimos a Eisenstein. O espaço possui uma organização estética que não é, portanto, ditada somente pelo som, mas pela construção plástica de todos os códigos ${ }^{53}$ utilizados para a construção da cena.

A tensão provocada no espectador pelo ritmo acelerado da música, o frenesi da multidão em fuga na escadaria de Odessa são geradas pela combinação conflituosa dos planos. Mas não é só isso. A dramaticidade dessa tomada específica nasce não só da articulação entre os planos, mas também da montagem interna da cena. Ao postergar o tempo de duração da cena, Eisenstein cria no espectador a sensação de que a escadaria possui um tamanho gigantesco e perturbador.

Nessa cena da escadaria, o que parece ficar patente é, de um modo geral, a ideia de provocar o afloramento do drama no espectador por intermédio da montagem do filme. Há, sem dúvida, um atordoamento de nossa percepção ótica e tátil. Não só por conta do atrito dos planos entre si, mas do choque dos

52 EISENSTEIN, op. cit., p. 81.

53 Código deve ser entendido aqui como sistema de transferência de significado. 
mesmos com os espectadores. O que parece estar em jogo é, portanto, a ideia de nos tornarmos cúmplices da cena. O choque entre imagens díspares cria um forte impacto no espectador e, consequentemente, o sentido da cena ao qual se queria chegar. Esse sentido seria o de fundir o filme com a plateia. Em $O$ sentido do filme, Eisenstein faz o seguinte comentário sobre a relação entre espectador e filme:

Na realidade, todo espectador, de acordo com sua individualidade, a seu próprio modo, e a partir de sua própria experiência - a partir das entranhas de sua fantasia, a partir da urdidura e trama de suas associações, todas condicionadas pelas premissas de seu caráter, hábitos e condição social - cria uma imagem de acordo com a orientação plástica sugerida pelo autor, levando-o a entender e sentir o tema do autor. É a mesma imagem concebida e criada pelo autor, mas esta imagem, ao mesmo tempo, também é criada pelo próprio espectador. ${ }^{54}$

Em outros termos, o que Eisenstein faz em seus filmes é soldar uma série de elementos para criar ideias que rompem com o campo da expressão verbal-linguística. Pela montagem, essas ideias são mescladas para gerar o que Dudley Andrew chama de "um grande evento emocional sincrético, um evento capaz de reorientar nosso pensamento e nossa ação". ${ }^{55}$

Diante do exposto, não é de se estranhar o fascínio de Benjamin pela arte do cinema. Além da montagem, outro fator que pode ter contribuído para o apreço de Benjamin pelo cinema

54 EISENSTEIN, op. cit., p. 28.

55 ANDREW, op. cit., p. 57. 
seria uma relação deste último com a tradição literária, da qual Eisenstein é tributário tanto quanto Benjamin. Em seu $A$ forma do filme, Eisenstein menciona a literatura como fonte importante de conhecimento para sua formação. "Acho que além de dominar os elementos da dicção cinematográfica, a técnica do plano e a teoria de montagem, temos outro ganho a citar - o valor dos laços profundos com as tradições e metodologias da literatura". ${ }^{56}$ Após tudo o que vimos até o momento, vejamos o que mais pode ser dito a respeito desse fascínio.

Ao produzir um filme, Eisenstein sabe que o diretor tem as rédeas do filme em suas mãos, mas toda a sua teoria visa tirar o espectador de uma posição passiva para uma ativa. No cinema, temos implícita a ideia de experimentar algo por intermédio da imagem. E o que se experimenta? Se, de um lado, a forma de outros tipos de cinema capta a atenção de Benjamin, como o de Chaplin ou dos desenhos de Walt Disney, pois, se assim não fosse, estes não seriam elencados por ele no ensaio "A obra de arte na era de sua reprodutibilidade técnica", de outro, o cinema russo parece carregar aquilo que Benjamin preza mais na arte desauratizada que é a fusão do público espectador com a obra. Como observamos, os planos puros em si não nos dizem nada. Não só para Eisenstein, mas para Benjamin também.

Dentre as funções sociais do cinema, a mais importante é a de estabelecer o equilíbrio entre o homem e o aparato. Essa tarefa o cinema a cumpre inteiramente, não só pelo modo como o homem se representa perante o aparato de registro, mas também

56 EISENSTEIN, op. cit., p. 25. 
pelo modo como representa para si o mundo circundante com ajuda desse aparato. O cinema, por meio dos grandes planos retirados do inventário do mundo circundante, por meio da ênfase dada a detalhes ocultos nos adereços que nos são comuns, por meio da investigação de ambientes banais sob a direção genial da objetiva, por um lado, amplia a perspectiva sobre as necessidades que regem nossa existência e, por outro, chega ao ponto de nos assegurar um enorme e insuspeitado espaço de jogo. ${ }^{57}$

E, no parágrafo seguinte do ensaio sobre $A$ obra de arte, Benjamin complementa:

Nossos bares e ruas de grandes cidades, nossos escritórios e quartos mobiliados, nossas estações de trem e fábricas, pareciam nos encerrar sem esperança. Então, veio o cinema e explodiu esse mundo encarcerado com a dinamite dos décimos de segundo, de tal modo que nós, agora, entre suas ruínas amplamente espalhadas, empreendemos serenamente viagens de aventura. Com o grande plano, o espaço se dilata, com a câmera lenta, o movimento. [...]. Desse modo, torna-se evidente ser uma a natureza que fala à câmera e outra a que fala aos olhos. ${ }^{58}$

Apesar do poder da montagem, ela não nos diz tudo. Sem a experiência da plateia para atribuir significado à película, a obra seria um mero ato subjetivo de um diretor. "[...], Eisenstein sempre insistiu na ajuda do espectador ao se forjar o significado do filme. Nisso, obviamente, sua teoria lembra as teorias do teatro

57 BENJAMIN, op. cit., p. 95-97.

58 ENJAMIN, op. cit., p. 97-99. 
que Bertolt Brecht estava elaborando". ${ }^{59}$ É a partir de pequenos atos como aqueles que compõem a trama do Encouraçado que se pode gerar um sentimento coletivo de insurgência contra o status quo da sociedade capitalista.

\section{Considerações finais}

Antes de concluirmos, o que precisa ser dito porque ficou esquecido nas páginas anteriores é que Benjamin não é nada saudosista a respeito de todo esse processo de esfacelamento da aura na contemporaneidade e, portanto, sobre a mudança na percepção das obras de arte na era da reprodutibilidade técnica. No subtítulo do ensaio dedicado ao tema da fotografia, ao mencionar os trabalhos de Atget, Benjamin já demonstra ser totalmente favorável a toda essa revolução estética e técnica. Segundo Gasché, "[...] é preciso notar que a importância que Benjamin atribui nesse capítulo à fotografia de Atget revela claramente que ele aprova sem remorsos uma arte que eliminou por completo o valor de culto em proveito do valor de exposição". ${ }^{60}$

A desauratização da obra de arte abre a perspectiva de uma autonomia cognitiva para o indivíduo, pois a reprodução técnica emancipa a obra do ritual contemplativo da arte aurática. Na visão de Bolz: "[...] o filme, diferentemente da obra de arte burguesa, não é objeto de contemplação, mas é o objeto, o instrumento, de um exercício prático". ${ }^{11}$ Ademais, o fim da aura pôde abrir caminho para uma forma política de arte. Como isso ocorreria? Na medida

59 ANDREW, op. cit., p. 61.

60 GASCHÉ, op. cit., p. 201.

61 BOLZ; FONTAINE, op. cit., p. 96. 
em que o cinema é feito para as massas, abre-se, de imediato, a possibilidade do mesmo ser utilizado para fins políticos. De acordo com Gasché, "O conteúdo que esses espectadores do cinema vêem não é a representação de alguma realidade exótica (geográfica ou social) fascinante, mas, como o demonstra a ênfase de Benjamin nos filmes russos, são eles mesmos como atores, e como trabalhadores a trabalhar". ${ }^{62}$ Assim, se, por um lado, podemos encontrar no ensaio, um Benjamin consciente de que o homem voltado inteiramente para a interceptação do choque das imagens na sala de cinema não tem energia livre para uma autoreflexão, ou seja, a dinâmica operacional do cinema impede que o espectador se entregue às suas próprias associações de ideias, por outro, há um Benjamin que não enxerga esse processo como algo necessariamente negativo. Essa nova sensibilidade promovida pela experiência do cinema abre caminhos para uma perspectiva política da obra de arte tecnicamente reprodutível.

Benjamin analisa o cinema no âmbito da reprodutibilidade técnica e da democratização do conhecimento, não sem antes proceder a uma modificação de seu sentido, rompendo com a perspectiva que atribui às massas um déficit conceitual e uma maior sensibilidade às imagens. Frequentemente se diz que as massas não refletem, mas sentem, considerando-se que comover-se e raciocinar são atitudes contraditórias, como se fosse possível cogitar sem afetos ou paixões. O cinema permitia integrar as paixões na racionalidade política. ${ }^{63}$

62 GASCHÉ, op. cit., p. 206.

63 MATOS, Olgária Chain Féres. Benjaminianas: cultura capitalista e fetichismo contemporâneo. São Paulo: Unesp, 2010, p. 228. 
Conforme atestado anteriormente, os filmes de Eisenstein são exemplos de um tipo de cinema aceito por Benjamin por terem uma proposta crítica da realidade. Se há alguma função política no cinema, esta, como nos diz Rouanet, "não está em condicionar espectadores distraídos, mas em descondicionar espectadores manipulados". ${ }^{64}$

No mesmo período histórico, em linha oposta ao cinema libertador de Eisenstein, temos o cinema fascista que busca captar o rosto das massas em seu estado natural diante da câmera. Ao fazêlo, um dos principais propósitos do cinema fascista é mobilizar as massas para o esforço de guerra. Nesse caso específico, o aparelho cinematográfico não serve para ampliar a perspectiva de vida das massas, isto é, para sugerir uma modificação nas relações de produção e, por consequência, no modo de vida dos indivíduos. Além da manutenção do status quo, o retrato do rosto das massas serve como propaganda política. O objetivo desse retrato no cinema fascista é incorporar a guerra ao circuito natural da vida humana. O que o cinema fascista promove é, portanto, a estetização da guerra. Em outras palavras, o fascismo promove o embelezamento da guerra, isto é, da destruição e esse embelezamento nasce, segundo Buck-Morss, da alienação sensorial do indivíduo. "Benjamin diz que a alienação sensorial encontra-se na origem da estetização da política, a qual o fascismo não cria, apenas 'maneja' (betreibt)". ${ }^{65} \mathrm{O}$ cinema pode assim ser usado para fins auráticos como foi o caso do cinema fascista e Benjamin tinha conhecimento desse fato quando escreveu "A obra de arte na época de sua reprodutibilidade técnica". "O

64 ROUANET, op. cit., p. 62.

65 BUCK-MORSS, op. cit., p. 156. 
cinema é portanto uma arte potencialmente não aurática, embora Benjamin também se dê conta de que ele pode ser usado para fins auráticos". ${ }^{66}$

O fascismo pode colocar a tecnologia a serviço de uma arte cinematográfica aurática no sentido de que os indivíduos "participam avidamente de sua própria história ao mesmo tempo em que a assistem como a história de outrem; participam da ação política e a veem de longe; participam de sua própria destruição e se deleitam com o espetáculo (...)" ${ }^{67}$ Esse fenômeno do cinema fascista relatado por Caygill pode ser detectado em $O$ triunfo da vontade de Leni Riefenstahl. Nele, as massas se aglutinam em um estádio de Nuremberg para uma sessão de cinema, sem se darem conta da finalidade real da reunião que seria a contemplação da destruição e da morte de seres humanos em massa. Em "Estética e anestética: uma reconsideração de 'A obra de arte' de Walter Benjamin", Buck-Morss explica:

Num filme de Leni Riefenstahl de 1935, O triunfo da vontade (que Benjamin certamente conhecia quando escreveu $A$ obra de arte), as massas mobilizadas ocupam o terreno do estádio de Nuremberg da tela de cinema, de modo que os padrões superficiais proporcionam uma concepção agradável do conjunto, fazendo o espectador esquecer a finalidade daquela exibição, a militarização da sociedade para a teleologia de fazer a guerra. A estética permite uma anestesia da recepção, uma visão da 'cena' com um prazer desinteressado, ainda que essa cena seja a preparação de toda uma sociedade, por meio

66 CAYGILL, op. cit., p. 43.

67 CAYGILL, op. cit.., p. 44. 
de um ritual, para o sacrifício sem questionamento e, em última instância, a destruição, o assassinato e a morte. ${ }^{68}$

Quando Benjamin menciona no seu ensaio a manipulação capitalista da indústria cinematográfica com o propósito de ludibriar as massas dos reais problemas sociais que as atingem como as crises econômicas que geram um alto índice de desemprego e, ao mesmo tempo, dialeticamente contrapõe o cinema russo a este, o que o autor do ensaio faz é denunciar o caráter ideológico da apropriação capitalista. $\mathrm{O}$ cinema socializa a arte e, por consequência, pode permitir ao proletariado conhecer a sua posição de explorado no sistema capitalista.

$\mathrm{Na}$ Europa Ocidental, a exploração capitalista do cinema bloqueia a consideração do direito legítimo de ser reproduzido que o homem atual possui. Impede-a também o desemprego, que exclui grandes massas da produção, em cujo processo de trabalho essas massas encontrariam, em primeira instância, seu direito de ser reproduzido. Sob essas circunstâncias, a indústria cinematográfica possui todo o interesse em estimular a participação das massas por meio de representações ilusórias e especulações ambíguas. Com esse objetivo, mobilizou um poderoso aparelho publicitário: colocou a seu serviço a carreira e a vida amorosa dos astros, organizou plebiscitos, convocou concursos de beleza. Tudo isso para falsificar, por um caminho corrupto, o interesse originário e justificado das massas pelo cinema - um interesse de autoconhecimento e, com isso, de conhecimento de classe. Vale, portanto, em particular para o

68 BUCK-MORSS, op. cit., p. 190-191. 
capital cinematográfico, o que, no geral, vale para o fascismo: que uma necessidade inegável por novas condições sociais é explorada secretamente no interesse de uma minoria de proprietários. ${ }^{69}$

De acordo com Benjamin, no cinema, a técnica pode ser usada para algo além de acúmulo de capital. $\mathrm{O}$ indivíduo não mais sucumbiria ao ritual exaustivo dos processos da máquina nas fábricas, os quais drenam sua energia vital para a execução de trabalho alienado. A técnica perde assim seu caráter capitalista de exploração do corpo. Dentro ainda do próprio sistema capitalista de produção e, antes, portanto, do surgimento de uma sociedade socialista, a montagem cinematográfica oferece outro sentido para a técnica, isto é, um sentido para além da economia capitalista de produção e para além da mera comercialização de mercadorias. Tendo diagnosticado uma "pobreza de experiência" " assolando os indivíduos no início do século XX, pois, não há mais transmissão de experiências dos idosos aos mais jovens, seja "de modo benevolente ou ameaçador" $"$ e nem mesmo a Primeira Guerra Mundial foi capaz de gerar publicações nos dez anos seguintes que contivessem "experiências transmissíveis de boca em boca"72, com o seu ensaio A obra de arte, Benjamin não pretende resgatar essas experiências com o cinema. Todavia, isso não o impede de pensar o cinema como uma mídia capaz de se interpor entre o processo

69 BENJAMIN, op. cit., p. 81-83.

70 BENJAMIN, "Experiência e pobreza". In: BENJAMIN, Magia e técnica, arte e política: ensaios sobre literatura e história da cultura. p. 118.

71 BENJAMIN, op. cit., p. 114.

72 BENJAMIN, op. cit., p. 115. 
de pauperização da experiência e a consequente barbarização da natureza humana. Essa ideia benjaminiana sobre o cinema não se faz presente no ensaio "Experiência e pobreza" de 1933, mas a percepção perturbadora de que a crise econômica da Alemanha poderia abrir as portas para uma nova guerra aparece tanto neste ensaio sobre a pobreza de experiência como está explícita no ensaio "A obra de arte na era de sua reprodutibilidade técnica".

Nos encaminhamos agora definitivamente para o terreno das considerações finais. O mérito do ensaio de Benjamin seria o de estimular no leitor uma reflexão sobre as transformações técnicas experimentadas nas obras de arte e o potencial emancipatório da reprodução técnica para as massas. A questão seria a seguinte: em que medida uma arte reprodutível como o cinema tem potencial suficiente para implodir os pilares das relações capitalistas de produção, isto é, a sociedade como um todo pode ser transformada pela arte de massas? Ora, se, para Benjamin, há potencial político no cinema e, por conseguinte, seria preciso aceitar que a emancipação depende da técnica, isso significa que o despertar da consciência deveria conduzir as massas, por intermédio da técnica, a desenvolverem novas possibilidades para as forças produtivas, visando a satisfação verdadeira das necessidades humanas.

Do ponto de vista puramente estético, o alargamento de nossa percepção nos permitiria somente ir até o limite de contrapor uma arte aurática para poucos e uma arte pós-aurática em que as massas têm vez, rompendo-se assim com os privilégios antigos no acesso às obras de arte. No campo da política, além do fim desses privilégios, ato que poderia ser considerado em si mesmo político, o potencial técnico poderia gerar novas formas de sociabilidade entre os indivíduos da massa e poderia fazer com que estes não aderissem de forma tão incisiva à realidade imediata imposta pelo capitalismo, isto é, se romperia com a ingenuidade e submissão voluntária à 
lógica de mercado que tudo pretende dominar, ponto central da teoria crítica. As novas técnicas de reprodução parecem, portanto, serem revolucionárias somente na medida em que ensejam nas massas um conhecimento capaz de modificar a estrutura petrificada das relações de produção existentes, isto é, se forem capazes de construir pensamento crítico suficiente para contestar a realidade social vigente de dominação da classe trabalhadora. 


\section{Referências bibliográficas}

ANDREW, Dudley J. As principais teorias do cinema: uma introdução. Trad. Teresa Ottoni. Rio de Janeiro: Jorge Zahar, 2002.

BAUMGART, Fritz. Breve história da arte. Trad. Marcos Holler. São Paulo: Martins Fontes, 2007.

BENJAMIN, Walter. A obra de arte na era de sua reprodutibilidade técnica. Trad. Francisco De Ambrosis Pinheiro Machado. Porto Alegre, RS: Zouk, 2012. . Pequena história da fotografia. In: BENJAMIN, Walter. Magia e técnica, arte e politica: ensaios sobre literatura e história da cultura. São Paulo: Brasiliense, 1996, p. 91-107.

. Experiência e pobreza. In: BENJAMIN, Walter. Magia e técnica, arte e política: ensaios sobre literatura e história da cultura. São Paulo: Brasiliense, 1996, p. 114-119.

BOLZ, Norbert W. e FONTAINE, Michael de la. Onde encontrar a diferença entre uma obra de arte e uma mercadoria? Revista USP, São Paulo, n. 15, p. 91-101, set/out/nov. 1992.

BUCK-MORSS, Susan. Estética e anestética: uma reconsideração de "A obra de arte" de Walter Benjamin. In: BENJAMIN, Walter et al. Benjamin e a obra de arte: técnica, imagem, percepção. Trad. Marijane Lisboa e Vera Ribeiro. Rio de Janeiro: Contraponto, 2012, p. 155-204.

CAYGILL, Howard. Benjamin, Heidegger e a destruição da tradição. In: BENJAMIN, Andrew e OSBORNE, Peter (Orgs.). A filosofia de Walter Benjamin: destruição e experiência. Trad. Maria Luiza X. de A. Borges. Rio de Janeiro: Jorge Zahar, 1997, p. 17-46

EISENSTEIN, Sergei. A forma do filme. Trad. Teresa Ottoni. Rio de Janeiro: Jorge Zahar, 2002. 
. O sentido do filme. Trad. Teresa Ottoni. Rio de Janeiro: Jorge

Zahar, 1990.

GAGNEBIN, Jean-Marie. De uma estética da visibilidade a uma estética da tatibilidade em W. Benjamin. In: COLÓQUIO INTERNACIONAL ESTÉTICAS DO DESLOCAMENTO: DISCURSO FILOSÓFICO, TEORIA CRÍTICA E LINGUAGENS ARTÍSTICAS. Belo Horizonte. 2007. Anais. Organização do CD-ROM: Rodrigo Duarte e Imaculada Kangussu. Belo Horizonte: Associação Brasileira de Estética (ABRE), 2008. p. 1-13.

GASCHÉ, Rodolphe. Digressões objetivas: sobre alguns temas kantianos em "A obra de arte na era de sua reprodutibilidade técnica" de Benjamin. In: OSBORNE, P. e BENJAMIN, Andrew (orgs.). A filosofia de Walter Benjamin: destruição e experiência. Rio de Janeiro: Jorge Zahar Editor, 1997.

LEONE, Eduardo e MOURÃO, Maria Dora. Cinema e montagem. $2^{\mathrm{a}}$ ed. São Paulo: Ática, 1993. (Série Princípios).

MATOS, Olgária Chain Féres. Benjaminianas: cultura capitalista e fetichismo contemporâneo. São Paulo: Unesp, 2010.

ROSEN, Michael. Benjamin, Adorno, e o ocaso da aura. In: RUSH, Fred. (Org.). Teoria crítica. Trad. Beatriz Katinsky e Regina Andrés Rebollo. São Paulo: Idéias \& Letras, 2008.

ROUANET, Sérgio Paulo. Édipo e o anjo: itinerários freudianos em Walter Benjamin. 2a ed. Rio de Janeio: Tempo Brasileiro, 1990.

SCHÖTTKER, Detlev. Comentários sobre Benjamin e $A$ obra de arte. In: BENJAMIN, Walter et al. Benjamin e a obra de arte: técnica, imagem, percepção. Trad. Marijane Lisboa e Vera Ribeiro. Rio de Janeiro: Contraponto, 2012, p. 41-154. 